\title{
Exploring the Role and Challenges of Ethical Values to Impart Good Governance: The Case of Dessie Town, South Wollo, Ethiopia
}

\author{
Yimer Ali \\ Department of Civics and Ethical Studies, Wollo University, Dessie, Ethiopia \\ Email address: \\ yimer.ali9@gmail.com \\ To cite this article: \\ Yimer Ali. Exploring the Role and Challenges of Ethical Values to Impart Good Governance: The Case of Dessie Town, South Wollo, \\ Ethiopia. International and Public Affairs. Vol. 4, No. 1, 2020, pp. 1-7. doi: 10.11648/j.ipa.20200401.11
}

Received: September 2, 2019; Accepted: October 26, 2019; Published: April 23, 2020

\begin{abstract}
The objectives of the study was to assess the role and challenge of realizing ethical values in promoting good governance. For this study the data was gathered from both primary and secondary sources. The primary sources of information was gathered through questionnaire and interviews whereas secondary data gathered from different types of documentaries, published materials and internet websites resources. The gathered data were analyzed and interpreted by using tables and percentages. As the study revealed, the overall objective of good governance is to ensure good conduct with the concern for values, practices and behavior. These values are inculcated in an individual by his/her parents, teachers, religion, society and the environmental of work place. The essential duty of governance principles is to effectively and equitably implement ethical values of the society. Hence, it demands highly competent, well administration, participatory and good deal of sound policy formulation and distinct citizen orientation. The promotion of ethical values in good governance implies legality of government action; rationality in policy and decision making; evolving a sense of responsibility; creating excellence; facilitating spirit of individual and organizational goals; developing responsiveness; protecting the national interests; and bringing and elevating integrity. The study identified the role and challenge of realizing ethical values in promoting good governance in Dessie Town. It is recommended by the researcher that the officials and religious institutions must give high consideration to ethical values and principles for realization of good governance in the study area.
\end{abstract}

Keywords: Challenge, Ethics, Morality, Good Governance, Promotion

\section{Introduction}

Ethics means mood, nature, temper, and such things which are used as inner part of human and it can be understand by insight in comparison to "people" which is used to appearance of human and it can be see with eyes. Also ethics has been defined as the collection of human spiritual and inner characteristics which arise from inner features of human. Ethical values are a set of values that govern virtuous behaviors, actions and characters of an individual. Ethical values are important to determine our character and they are central to our profession and guide our lives as we serve our nation [1]. The advancement of ethics and moral values in good governance suggests legality of government action, rationality in policy and decision making, evolving a sense of responsibility, ensuring accountability, strengthening work commitment, creating excellence, facilitating spirit of individual and organizational goals, developing responsiveness, showing compassion, protecting the national interests, protecting the spirit of justice, bringing transparency and elevating integrity. Actually, these values expect the controllers of ancient India to be the civil servants of modern India that are guided by a spirit of service [17].

Ethical values are a set of rules, which an individual use to govern his /her activities and actions. Those are important to determine our behavior and they are central to our profession in order to guide our lives as we serve our nation. In other words, Ethical values are a means to evaluate the actions of professional by encourage individuals in an organization to make decision based on the stated beliefs and attitudes towards their practices. In addition, it helps to creating ethical work place and encourages professionals to perform 
their job responsibility accordingly [2]. The 1995 constitution of Ethiopia instituted radical reform of governance structure including devolution of significant resources and responsibilities from central agencies to nine regional administrations. An explicit goal of the new constitution is to bring government closer to the people through a process of decentralization intended to increase public participation and responsiveness to the local needs. Municipality is one of local area with its own incorporated government for local affairs and its governing officials. It is a political unit, such as a city, town, or village and is a body of officials appointed to manage the affairs of local political unit. Municipality also defined as a political subdivision of a state with in which a municipal corporation has been established to provide general local government for a specific population concentration in a defined area [3].

Good governance perceived as a normative principles of administrative law; which obliges the state to perform its function that promote the values of efficiency; noncorruptibility and responsiveness to civil societies. It also epitomized by predictable open and enlightened policy making, a bureaucracy imbued with a professional ethos; an executive arm of government; which are accountable for its actions; and a strong civil society participating in public affairs; and all having under the rule of law. It encompasses the role of public authorities in establishing the environment in which economic operators function and in determining the distribution of benefit and burdens as well as the relationship between the ruler and the ruled. It also effective and equitable, participatory, transparent, accountable and promotes the rule of law. Hence, the practice of good common moral values like kindness, compassion, honesty, and justice, etc. is not dependent on economic or technological development and on the standard of living [4].

According Richard (2006), better governance promotes gender equality; sustains the environment; and provide tools to reduce poverty, deprivation, fear and violence. In recognition of the imperative of good governance for development; African countries have made remarkable strides and commitments towards good governance in Africa. Evidence from the past decades; since the 1980s' showed that in exception of few countries such as China, Malaysia and Singapore have made progress. In the majority of countries in Africa, China and Latin America; have poor governance with a cause of continuous poverty and underdevelopment. African countries have taken a number of necessary and bold initiatives on governance as one of the essential elements for sustainable economic development for the alleviation of poverty, but these initiatives are still constrained by a number of critical challenges that should be tackled to enhance the prospects of good governance. Good governance and ethical values are highly interdependent concepts. Good governance promoted through laws and codes of conduct. Correspondingly unethical behavior and misconduct are considered as a challenge of good governance. In general, ethical values are a crucial instrument for an individual by expressing what is right and wrong action. Thus, good governance can be promoted through the improvement of ethical values [5].

Ethical Values are individual reliefs that motivate people act one way or another. They served as a guide for human behavior and make ethical choices in life. Generally, people are predisposed to adopt the values that they are raised with people also tend to believe that those values are "right" because they are the values of their particular culture. Theses becomes more relevant in cities like Dessie, where the population flives in love, wisdom, tolerance and faithfully. Ethical decision-making often involves weighing values against each other and choosing which values to elevate. Conflicts can result when people have different values, leading to a clash of preference $s$ and priorities. Some values have intrinsic worth, such as love truth, and freedom. Other values, such as ambition, responsibility, and courage, describe traits or behaviors that are instrumental as means to an end. Still other values are considered sacred and are moral imperatives for those who believe in them. Sacred values will seldom be compromised because they are perceived as duties rather than as factors to be weighted indecision-making [6]. The study focused on the Ethical values and good governance by examining the role it played and complexity to the florishment of good governance in Dessie town, South Wollo, Ethiopia.

\subsection{Statement of the Problem}

Good governance guarantees political, social and economic priorities on the basis of the aspiration of the public; and the most marginalized groups are given priority in decision making over the distribution and provision of development resources. By generating and defending broad commitment to the public welfare; a high quality democracy with good governance increases the likelihood that public resources would be used to generate public goods that stimulate investment and commerce and raise the quality of life. Therefore, good governance is promoting values for an organization; and demonstrating those values through behavior and putting them in to practice. Ethical values should become a habit and effective values to promote good governance by testing the action and character of an individual as well as professionals; and form the basis for all policies, procedures, and actions of its governing body members and other staff. Those values are more general and universal in nature. In other words, ethical values are a set of guiding principles that encourage individuals in the organization to make decision [7].

There are several international charters, conventions, declarations, and decisions which African countries struggle to implement good governance. In this endeavor, they are confronted with various limitations in human and financial resources. In the way forwarded, there is a need for reliable external resources to support all process of governance to make it sustainable. Even though, there is an intensive focus on replacing bad governance with good, and on the reform of political, economic, social and legal structures, it has been significant progress, but the way ahead is potholed with challenges [8]. 
Improved governance requires an integrated, long-term strategy built upon cooperation between government and citizens. It involves participation and institutional building that can serve all societies without difference. The Rule of Law, Accountability, and Transparency are technical and legal issues at some levels, but also interactive to produce government that is legitimate, effective, and widely supported by citizens, as well as a civil society that is strong, open, and capable of playing a positive role in politics and government. Therefore to implement the concepts effectiffely the growing urbanization and migration in Dessie the town is becoming crowded and the already endowed values are degraded gradually. In consideration of this the municipality is failed to promote sustainable human values and atmosphere which is highly conducive to stability, and anticorruption management system. The accountability and transparency of institutions are promulgated in the absence of complementary and supportive mechanisms of societal values and extra governmental structures. There have been a number of valuable studies on good governance and ethics. However, there is no research on the role and challenge of realizing ethical values in promoting good governance in the study area. Therefore, this paper tried to identify the role and challenge of realizing ethical values in for the promotion of good governance principles in Dessie.

\subsection{Objectives of the Study}

\subsubsection{General Objective}

Generally, the study was to explore the role and challenge of realizing ethical values in promoting good governance in Dessie Town Municipality.

\subsubsection{Specific Objective}

1) To identify the existing situation of good governance and ethical values in Dessie town;

2) To analyze the relationship between good governance and ethical value in Dessie town;

3) To assess the challenges of maintaining societal values and good governance principles in Dessie Town Municipality;

\subsection{Research Question}

1) What is the existing situation of good governance and ethical values in Dessie town?

2) What is the relationship between good governance and ethical values Dessie town?

3) What is the challenge for maintaining societal values and good governance principles Dessie town Municipality?

\section{Research Methodology}

\subsection{Research Design}

Research design is essential as it determines the method of data collection; data source; and the sample methodology. In attempts to assess the role and challenge of realizing ethical values in promoting good governance; the researcher was incorporate both approaches (i, e, quantitative and qualitative approaches). This is in order to address different objective of the study, as part of the overall design, research design was used. According to (Creswel, 2006); mixed research design is a type of design used to obtain both quantitatively and qualitatively concerning the current status of the phenomena to describe "what exists " with respect to variables in a situation.

\subsection{Data Collection Instrument}

In order to gather the required data the researcher used both Questionnaire and interview data collection instruments. The researcher was prepared well-structured questions for 37 respondents and includes both open ended and closed ended questions which were administered to get information concerning the existing situation of ethical values. The closed ended questions was used to capture direct answers from respondent's. while the open ended questions require reflection on the existing situations and allow the respondents to express their views. It could helped to the researcher to triangulate the information obtain through closed ended questions. Interview was employed to conduct information to support data which are collected through questionnaire. For interview 15 Participant was selected thorough judgmental method (purposive sampling method). Those interview participant were elders lived in the city for long period of time and observed cultural and socio economic changes for a decades.

\subsection{Method of Data Analysis and Interpretation}

After collecting the necessary data through various techniques, the researcher analyzed and interpreted the obtained data through various mechanisms. Therefore the obtained data were analyzed and interpreted by sorting out the information and by giving meaning to those data based on the approach of quantitative research method using tables and percentages. In addition, the qualitative data was presented in narrative form.

\section{Result and Discussion}

\subsection{Socio-Demographic Characteristics of Respondents}

The participants distributions were based on socio demographic characteristics such as Sex, age, and education level were selected and analyzed in the following tables.

Table 1. Sex and Age of the Respondents.

\begin{tabular}{llll}
\hline Variable & & Frequency & Percentage \\
\hline \multirow{3}{*}{ Sex } & Male & 20 & 54 \\
& Female & 17 & 46 \\
& Total & 37 & 100 \\
Age & $20-33$ & 18 & 49 \\
& $34-46$ & 11 & 30 \\
& $46-55$ & 8 & 21 \\
& 55 and above & - & - \\
\hline
\end{tabular}

Source: Survey, (2019). 
As presented in the table above, 20 (54\%) of the respondents were Male and $17(46 \%)$ of the respondents were Female. $18(49 \%)$ of the respondents were found in the age interval of between $20-33 ; 11(30 \%)$ of the respondents were found in the age interval of between $34-46 ; 8$ (21\%) of the respondents were found between 47-55; and none of the respondents responded for 55 and above. Therefore, most of the respondents were male in the study area, because as a matter of fact, most of the respondents were found to be in male population. And most of the respondents were in the age interval of between 20 and 33 in the study area

Table 2. Educational Level of the Respondents.

\begin{tabular}{lll}
\hline Educational Level & Frequency & Percentage \\
\hline Illiterate & - & - \\
Primary education & 9 & 24 \\
Secondary education & 17 & 50 \\
Diploma & 8 & 18 \\
Degree & 3 & 8 \\
MA and above & - & - \\
Total & 37 & 100 \\
\hline
\end{tabular}

Source: survey, (2019).

The above table 2 presented the level of education of the respondents. $17(50 \%)$ of the respondents were completed secondary education; $9(24 \%)$ of the respondents were completed primary education; $8(18 \%)$ of the respondents have diploma; $3(8 \%)$ of the respondents have degree; and none of the respondents were illiterate and MA and above. Therefore, $50 \%$ of the respondents were complete secondary education. So, I can say most of the respondents in the study area were educated.

\subsection{Analysis of Ethical Values In Order To Promote Good Governance Principles}

Globally moral values and ethical standards are shared by all faiths, like the respect of human rights, love, compassion, environment protection, integrity and accountability. And, there are a number of behaviors which are regarded by all faiths as sinful. Corruption, for example, is viewed as being equivalent to stealing other people's money and lying to the public. No world religion, no faith and no philosophical belief system allows stealing and lying. For instance in Islam, Prophet Muhammad clearly stated that "it is bribery to give gifts to an officer (in return for a favour)". He even predicted that "the one who gives bribes and the one who is bribed will be in hell".

Table 3. The practice of Good Governance in Dessie city.

\begin{tabular}{lll}
\hline $\begin{array}{l}\text { Do you believe that there is good } \\
\text { governance practices in Dessie Town? }\end{array}$ & Frequency & percentage \\
\hline Yes & 6 & 16 \\
No & 31 & 84 \\
Total & 37 & 100 \\
\hline
\end{tabular}

Source: Survey, (2019).

As shown in the above table, $31(84 \%)$ of the respondents were responded for their disaffection on the practice of good governance in institutions. while $6(16 \%)$ of the respondents were responded Yes, that means they are saying there is good governance in the study area. This indicates, the majority of the population in the study area was dissatisfied and unhappy by the good governance practices of government institution in the town. Concerning the issue the interviewee also mentioned the lack of human right protection; corruption; does not have access to opportunities and information; low budget to ensure social, economic political requirement; and weak system of accountability including inappropriate time management are constraints that impede the flourishment of effective governance in the study area.

According to UNDP (2000), good governance is among other things, participatory, transparent, accountable, effective and efficient, promote rule of law and protect and preserve human right. It also ensures that an organization or partnership fulfills its overall purpose; achieves its intended outcomes for citizens and service users; and operates in an effective, efficient and ethical manner. Thus, the municipality was unable to fulfill the above listed function according to the respondents. Therefore, has some problem in relation to good governance in the study area. As interviewee respondents responded in prehistoric time of Ethiopia, the concept of good governance was conceptualized with monarchies. Therefore, ethical values in governance are attracting attention of all the people who talk of good governance. Indeed the general objective of morality is to ensure good governance with prime concern for respecting moral values, practices and behavior in the society. As the study revealed these moral values are inculcated in an individual by her parents, teachers, religion, society and the environment of workplace. Hence, for realization it demands a highly competent, well informed administration. It envisages the government institutions to become innovative, participatory and have a good deal of sound policy formulation, open-mindedness, and distinct citizen orientation.

\subsection{The Challenge of Good Governance and Ethics in Dessie Town}

According to the interviewee, the town municipality play crucial role in promoting good governance. It is the key instrument in all affairs of the town by giving appropriate solutions to the raised problems. But, the municipality has less public participation; fail to managing and modeling good conduct establishing standards of good governance and ethics and not on the better condition of providing leadership and build positive relationship. Thus, I can say the Municipality of the town were faced some challenges to deliver service to the entire society; and does not responsible to discharge their responsibility as shown above.

Table 4. The Response of Civil Servants to Hear societies Problem in the Municipality.

\begin{tabular}{lll}
\hline $\begin{array}{lll}\text { Do you get appropriate response to your } \\
\text { problem from civil servants? }\end{array}$ & Frequency & Percentage \\
\hline Yes & 9 & 24 \\
No & 28 & 76 \\
Total & 37 & 100 \\
\hline
\end{tabular}

Source: Survey, (2019). 
According to the above table, 9 (24\%) of the respondents were said yes $28(76 \%)$ of the respondents were said No for the appropriate response from the civil servant of the Municipality in the study area This point out that the Municipality has un effective approach to respond based on the societl values and principles. In the society like Dessie, where peoples prominently grown with Islam ic and Christian tradition the advancement of ethics and moral values are vital in promoting good governance and legality of government action, rationality in policy and decision making, evolving a sense of responsibility, ensuring accountability, strengthening work commitment, creating excellence, facilitating spirit of individual and organizational goals, developing responsiveness, showing compassion, protecting the national interests, protecting the spirit of justice, bringing transparency and elevating integrity. Actually, these values expect the controllers of ancient India to be the civil servants of modern India that are guided by a spirit of service. As literatures shows, ethics is an effort to direct human conduct and it helps individual in leading good life by applying moral principles. Ethics is elucidated as well based standards of right and wrong that prescribe what humans ought to do, usually in terms of rights, obligations, benefits to society, fairness, or specific virtues. In present scenario, ethics in governance are attracting attention of researchers, people who talk of good governance. The spread of democracy in various countries of the world has highlighted the issue of ethics in governance. The Overall purpose of ethics is to ensure good governance with prime concern for ethical principles, practices and behavior. Governance is described as the way an organization takes itself and the processes and structure that are used to realise its goals. Governance is also crucially concerned with how organizations relate to each other, how they relate to citizens and the way in which citizens are given a voice. The essential duty of governance is to effectively and equitably implement what is called the social contract. Changeover to liberalization and economic reforms, and to new types of managerial set-ups is a complex and difficult task which demands a highly competent, well informed and caring administration. It is said that ethics and moral values can bring good governance and maximum public welfare in cities therefore government and private employs must promote ethical practices in administration [17].

Table 5. The Role of Municipality to alleviate societal problems and keeping ethical values.

\begin{tabular}{lll}
\hline $\begin{array}{l}\text { Do you have municipality give enough } \\
\text { solution to the raised problems from the } \\
\text { societies? }\end{array}$ & Frequency & Percentage \\
\hline Very high & 8 & 21 \\
High & 7 & 19 \\
Medium & 8 & 39 \\
Low & 14 & 21 \\
Total & 37 & 100 \\
\hline
\end{tabular}

Source: Survey, (2019).

As the above table shown that $14(39 \%)$ of the respondents were replied Low $8(21 \%)$ of the respondents replied very high $7(19 \%)$ of the respondents were replied high and the other $8(21 \%)$ of the respondents were replied medium role of the government institution in serving the pople based on the law and values. Therefore, it implies that that the town's Municipality is too late to decide solutions accordingly the people's integrity; and the Municipality fail to do their work properly. According to the interviewee, the municipality has less contribution to open its action, procedures, mechanisms and activities for the people in order to get compliance for its policies, strategies and programs. The municipality also did not provide necessary feedbacks to address the common goal of society and were unable to open its decisions and policies on the disclosure of information to its employees and public.

During interview the respondents urged the leaders to become more responsible for the future of country and humankind and contribute to reduce the social sins described above in our societies. When it realized our children, grandchildren and great grandchildren could be really thankful to us. If we fail to transfer, they have all reason to despise us. In connection with this, without effective leadership and Good Governance at all levels in private, public and civil organizations, it is arguably virtually impossible to achieve and to sustain effective administration, to achieve goals, to sustain quality and deliver first-rate services. The increasing complexities and requirements arising from the constant change in society, coupled with the constant push for higher levels of productivity, require effective and ethical leadership. Good governance and effective-ethical leadership are the essential requirements for an organization to be considered successful in the eyes of all stakeholders in the 21 st century. [16]

Table 6. The Extent of Discrimination among Clients.

\begin{tabular}{lll}
\hline $\begin{array}{l}\text { Do you have discrimination like sex, } \\
\text { race, religious etc shown? }\end{array}$ & Frequency & Percentage \\
\hline Highly shown & 8 & 22 \\
Shown & 19 & 51 \\
Sometimes shown & 6 & 16 \\
Not shown & 4 & 11 \\
Total & 37 & 100 \\
\hline
\end{tabular}

Source: survey, (2019).

As shown in the above table 19 (51\%) of the respondents said, there was discrimination in the Municipality; 8 (22\%) of the respondents said, the discrimination was high; $6(16 \%)$ of the respondents said, the discrimination was frequently happened; and $4(11 \%)$ of the respondents said, there was no discrimination in the study area.

Therefore, as the majority of the respondents confirmed that there is discrimination regarding race, sex, color, religious etc. This indicates that the problems in relation to impartiality in the Municipality and the office and legal framework could not be fair in the study area. The researcher also observed that, now a days in any government in institution service delivery depending on the the kinship, friendship and material prosperity of peoples. This contradicts with age old ethical values of love, tolerance, accommodation and impartiality. As presented by the 
interviewee, ethics provide for the professionals as a means of integrating rights and duties of them to build efficient and effective governance in the city. Even if civil servants in the municipality have their own work ethics, discipline and possession of skills to provide service in relation to the client's interest and demand, most servants becoming reluctant to serve. However, there are few professionals who were not willing to provide and treat clients in a good conduct and ethical behavior. Most civil servants also measure good governance with the salary of intuitions in the city. Therefore those intuitions failed to pay sufficient salary usually subject to hate and abuse.

\section{Conclusion and Recommendation}

\subsection{Conclusion}

As the study indicated, the advancement of ethical values can promote good governance and legality of government action, rationality in policy and decision making, ensuring accountability. It also strength civil servants the work commitment, creating excellence, facilitating spirit of individual and organizational goals, developing responsiveness, protecting the national interest and bringing transparency. As good governance and its principles concern for the issues of public administration, they certainly have related to the public sector ethics as well. Transparency and accountability are the most indicator of good governance as well as elements of ethical values that can bind the two concepts to the combined efforts of the city in poverty reduction. If the activities of government are transparent and officials and civil servants are held accountable for their decisions then the chances for effective services will be increases. Ultimately, the question for organizational transformation must begin with a personal commitment within each individual to pursue ethical excellence. Therefore, the establishments of ethical values are a central condition to build good governance in the institutions. In the city ethics and values are important in every aspect of societal life to determine what is right and what is important. However in the world of intense competition, every business entity work on certain principles and beliefs which are nothing but the values. Likewise, ethical values implemented in governmental or nongovernmental organization to ensure the protection of the interest of stakeholders like customers, suppliers, employees, society, students and government to use all resources effectively.

In Dessie town, most civil servants becoming unaccountable and untransparent to effective public service delivery; corruption mitigation effort; participation and responsiveness to the public need. These listed principles are the components of ethical values as well as good governance. Furthermore, currently the young generation neither abide by these moral and ethical values nor the existing rules and regulation. On the other hand, the principle of good governance in relation to ethical values can be operational through equity, transparency, accountability, responsiveness, rule of law, leadership etc. Therefore, ethical values of the society has a potential to foster trust; articulate the management system; and are building ladder for good governance.

\subsection{Recommendation}

On the bases of the summary of findings, the following recommendations are forwarded to the city administration and other concerned bodies:

1) Building ethical climate in the work place is very important to monitor and evaluate actions of professionals and build good governance; which ensures accountability, transparency, and treat equally without any bias and discrimination. To this end individual, religious scholars and government should lay foundation to ensure the empowerment of citizens and their participation in the development process.

2) A commitment to build, strengthens, and consolidates the system of democracy and good governance in any administration system is essential. Therefore higher education institutions must teach citizens to maintain ethical principles at large and guide their private and professional life in accordance with the principle of good governance.

3) Elders and religious leaders should teach the young generation to keep the established moral standards, to keep the environment clean and to stand to awake the society to stance against all form of mal practices, corruption and bad governances in sectors.

\section{References}

[1] Allen (1999) Value and Virtue in Public Administration: A Comparative Perspective, Palgrave Macmillan.

[2] Paul, Richard (2006) The Miniature Guide to Understanding the Foundations of Ethical Reasoning, United States: Foundations for Critical Thinking Free Press.

[3] World Bank Institute (2002) Social Accountability in the Public Sector: A Conceptual Discussion and Learning Module, Washington DC.

[4] Peter Schier (2004) On Moral Values, Ethical Standards, Leadership And Good Governance, Malaysian Institute of Management, Kuala Lumpur.

[5] NEPAD (2007) Governance in Africa's Development: Progress, Prospects and Challenges, Algeria.

[6] Andrews, M (2008) Good Governance Agenda, and Indicators without Theory, Oxford Development Studies.

[7] Dennis A. Pitta (1999) Ethical issues across cultures: managing the differing perspectives of China and the USA, University of Baltimore, Baltimore, Maryland, USA.

[8] Girindle, M (2004) Good Enough Governance, Poverty Reduction and Perform in Developing Countries, Governance: An International Journal of Policy Administration and Institution. 
[9] J Creswell (2009) qualitative, quantitative, and mixed methods approaches, University of Nebraska Lincoln.

[10] Joseph, R (1999) African Governance in the 1990s: Objectives, Resources and Constraints, Atlanta: Carter Center.

[11] Kidder, Rush worth (2003) How Good People Make Tough Choices: Resolving the Dilemmas to Ethical Living New York: Harper Collins.

[12] Thompson, Dennis (2012) Political Ethics, International Encyclopedia of Ethics, Hugh Lafollette, Black well.

[13] United Nations Development Program (UNDP) (2000) Strategy Note on Governance for Human Development.
[14] United Nations Development Program (2011) Human Development Report: Sustainability and Equity: A Better future for all, New York: UNDP.

[15] Abraham, R (2000) Discipline Democracy: Development Discourse and Good Governance in Africa, London: Led Books.

[16] Addisu Legas, (2019) Qualities of Effective Leadership and Its impact on Good Governance.

[17] Civil service India (2019) Strengthening of Ethical and Moral Values in Governance. 